\title{
Presentation and Comparison of Experimental Critical Heat Flux Data at Conditions Prototypical of Light Water Small Modular Reactors
}

\author{
${ }^{1}$ M. S. Greenwood, J. P. Duarte, and M. Corradini \\ University of Wisconsin-Madison \\ Department of Nuclear Engineering and Engineering Physics \\ 1500 Engineering Drive, Madison, WI 53706, USA \\ 1'greenwoodms@ornl.gov
}

\begin{abstract}
The Critical Heat Flux (CHF) is a two-phase flow phenomenon which rapidly decreases the efficiency of the heat transfer performance at a heated surface. This phenomenon is one of the limiting criteria in the design and operation of light water reactors. Deviations of operating parameters greatly alters the CHF condition and must be experimentally determined for any new parameters such as those proposed in small modular reactors (SMR) (e.g. moderate to high pressure and low mass fluxes). Current open literature provides too little data for functional use at the proposed conditions of prototypical SMRs.

This paper presents a brief summary of CHF data acquired from an experimental facility at the University of Wisconsin - Madison designed and built to study CHF at high pressure and low mass flux ranges in a $2 \times 2$ chopped cosine rod bundle prototypical of conceptual SMR designs. The experimental CHF test inlet conditions range from pressures of $8-16 \mathrm{MPa}$, mass fluxes of $500-1600 \mathrm{~kg} / \mathrm{m} 2 \mathrm{~s}$, and inlet water subcooling from $250-650 \mathrm{~kJ} / \mathrm{kg}$. The experimental data is also compared against several accepted prediction methods whose application ranges are most similar to the test conditions.
\end{abstract}

\section{KEYWORDS}

critical heat flux, small modular reactors, low mass flux 


\section{INTRODUCTION}

In 1937, Thomas B. Drew and Alfred C. Mueller presented a paper at the American Institute of Chemical Engineers meeting in Toronto exploring an interesting link largely dismissed by the scientific base at the time [1]. In this paper, the authors discuss how since man first put a pot of water on a fire it was known that the water would boil and the pot would, relatively, never be much hotter than the liquid inside it. Furthermore, if the temperature of the fire was increased, the violence of boiling would also increase. Although the Leidenfrost effect was known at the time, the authors noted that of all the investigators of heat transfer at the time, only Nukiyama appeared to recognize and investigate the existence of a 'maximum boiling rate' beyond which additional heating through a surface would actually decrease the heat transfer, exactly opposite the traditionally expected behavior. Nukiyama first presented his important findings and the first 'boiling curve' in the Japanese Journal Society of Mechanical Engineers in 1934 (reproduced in English for the first time in 1966 [2]).

More specifically, this boiling limit or Critical Heat Flux (CHF) condition is a two-phase flow phenomenon that is characterized by a flow regime change near a heated wall which rapidly decreases the efficiency of the heat transfer performance at the heater surface. The CHF condition is categorized by a local increase in vapor void fraction which covers the heater surface. The increased vapor void fraction triggers an abrupt and significant decrease in heat transfer rate between the heated surface and the two-phase coolant. The system response to a CHF event depends on the heat source; constant temperature or constant heat flux. The decrease in the heat transfer coefficient of a constant temperature heat source (e.g. steam heating) will cause the heat flux through the system to quickly decrease. A constant heat flux source (e.g. nuclear reactor, Ohmic heating) will have a rapid rise in the heating element wall temperature. The rise in temperature can lead to melting, enhanced chemical attack, and/or other metallurgical changes.

Since the initial recognition of the CHF condition, especially in the design and operation of nuclear reactors, significant resources have been spent establishing the conditions at which heat transfer deterioration is initiated. Decades of experience and thousands of data points have shown that the nature of a $\mathrm{CHF}$ condition is highly complex, requiring experimental data for any new parameters (e.g. geometries, testing conditions, materials, etc.) of interest. One developing application of nuclear power for which a dearth of data is available and therefore requires experimental support, rod bundle geometries in particular, is the Small Modular Reactor (SMR).

SMRs have been proposed as an alternative/complimentary solution to traditional power stations in meeting the 21st century world energy needs. In general these 'small' reactors are categorized according to an electrical output of $300 \mathrm{MWe}$ or less and lend themselves to modularity; the ability to fashion factory pre-fabricated components on site. Although numerous designs have been proposed [3], in general the nature of the SMR, with its enhanced focus on passive safety, lends itself to operate at much lower mass fluxes than traditional reactors along with high pressures that are either on par or slightly lower than traditional reactors. As this low mass flux and high pressure operating conditions have been of little interest till recently, there is limited to no data available that satisfies a multiple parameter criteria (i.e. pressure, subcooling, mass flux, non-uniform axial flux, and bundle geometry) 
necessary to predict $\mathrm{CHF}$ at the conditions expected to be relevant to SMRs. For example, Figure 1 and Figure 2 demonstrate the limited EPRI data [4] for a continuous non-uniform axial flux, square bundle geometry at the conditions covered in this paper. In total, the plot contains 193 data points, of which 149 contain a large unheated guide tube and 4 contain an unheated 'control' rod. Of particular note is the absence of data below a mass flux of approximately $1300 \mathrm{~kg} / \mathrm{m} 2 \mathrm{~s}$.

The remainder of this paper summarizes the experimental facility built at the University of Wisconsin and the gathered experimental data along with comparisons to a few widely accepted prediction methods in an effort to contribute to a public resource for SMR CHF conditions.
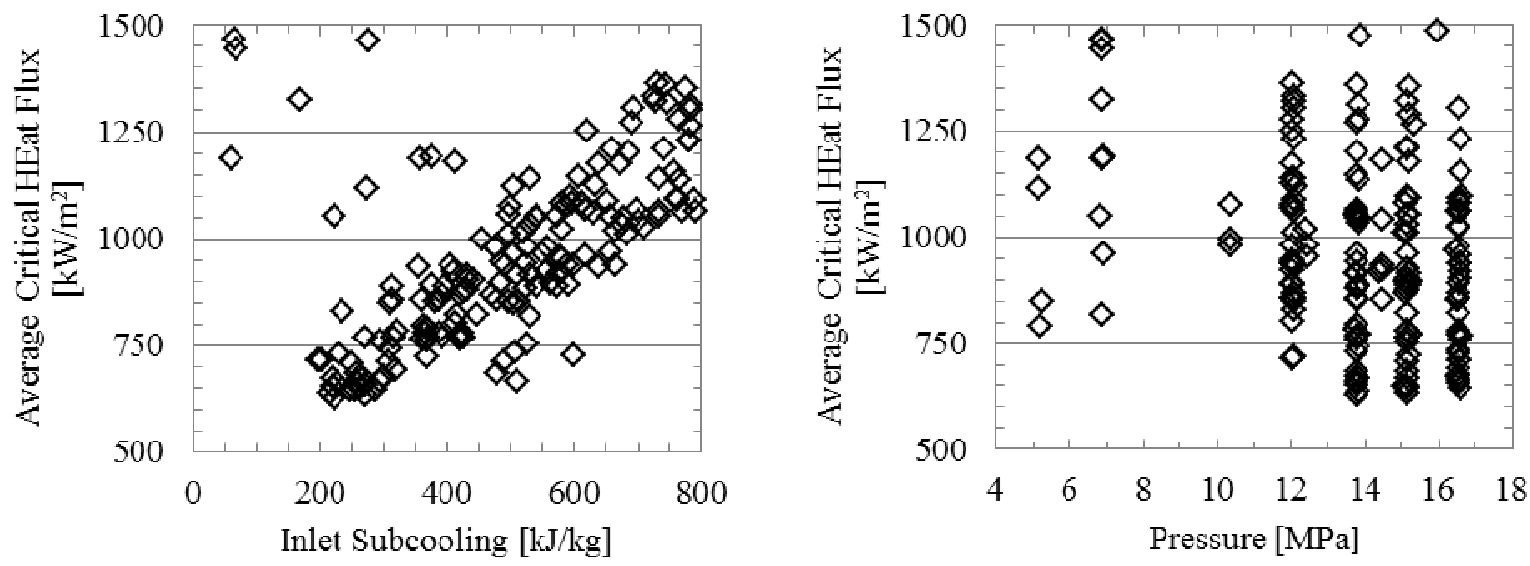

Figure 1. EPRI data for non-uniform heat fluxes, $P<17$ [MPa], and $G<1700[\mathrm{~kg} / \mathrm{m} 2 \mathrm{~s}]$.

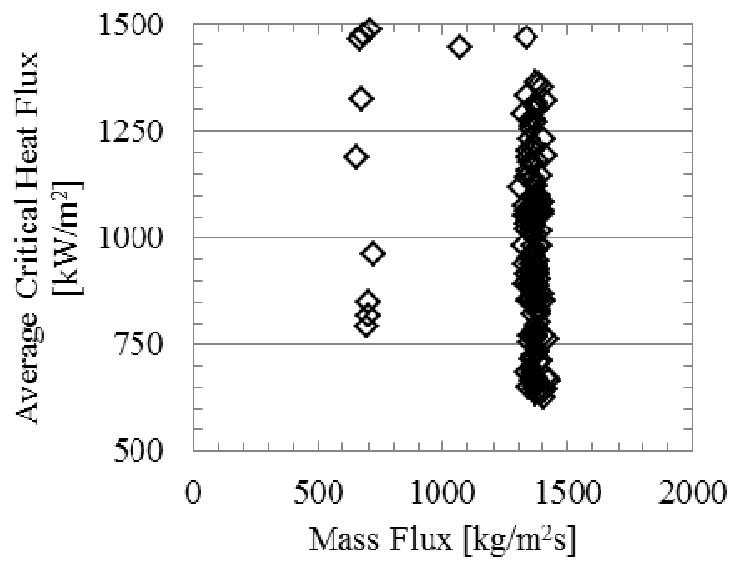

Figure 2. EPRI data for non-uniform heat fluxes, $P<17$ [MPa], and $G<1700[\mathrm{~kg} / \mathrm{m} 2 \mathrm{~s}]$.

\section{EXPERIMENTAL FACILITY}

\subsection{Overview}

The University of Wisconsin High Pressure Critical Heat Flux (UW-HPCHF) facility is a vertical forced circulation deionized water loop that passes through a $2 \times 2$ equally spaced non-uniformly heated rod 
bundle (Figure 3). The flow passes through a variable speed pump (1) to a the test section (4) and a bypass ( 3 ) which then recombine before passing through a shell and tube heat exchanger ( 5 and 6$)$ before repeating. The flow through the test section is measured with an orifice flow meter (2) while the facility pressure is maintained with a reservoir pressurized (7) with an argon cover gas (8) which also acts as the thermal expansion tank. Under the low flows under consideration, the pressure drop is expected to be minimal across the test section. Therefore, the pressure is measured at the inlet of the test section and assumed to be approximately constant throughout the test section.
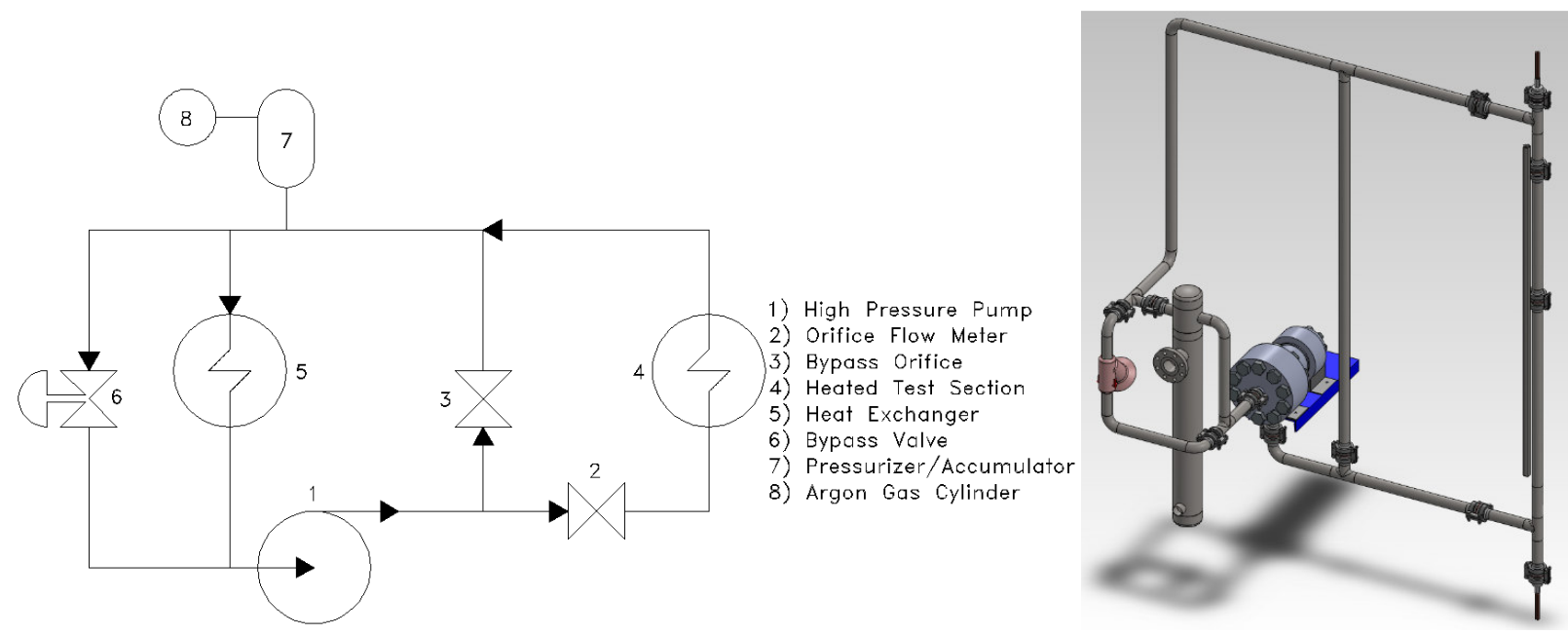

Figure 3. Basic process flow diagram and 3-D model (pressurizer not shown)

\subsection{Test Section}

The test section is comprised of four electrically heated elements with a chopped cosine power profile 2 $m$ in heated length $\left(L_{H L}\right)$ described by Equation 1 fixed within a square channel. The chopped profile is obtained with a helically cut tube with varying pitch (thinnest in the middle and thicker at the ends) while delivering a maximum per element power of $100 \mathrm{~kW}$. The specific dimensions of the heater elements and square test section are summarized in Table I. The channel wall is comprised of stainless steel 316 while the cladding of the heater elements is Monel K500. The geometry, power shape, and peak-to-average power ratio of the heaters were chosen to be representative of proposed SMR designs. Additional information and discussion of the facility can be found here [5].

$$
\frac{\mathrm{q}(\mathrm{x})}{q_{\text {avg }}}=\theta_{0}+\theta_{1} \cos \left(2 \theta_{2}\left[\frac{x}{L_{H L}}-0.5\right]\right)
$$

Given: $\theta_{0}=0.82 ; \theta_{1}=0.68 ; \theta_{3}=2.44 ; q_{\text {avg }}$ is the average heater power; $q(x)$ is the local power 
Table I. Summary of test section and heater element dimensions

\begin{tabular}{cccc}
\hline Parameter & Ratio & Parameter & Size (cm) \\
\hline Pitch/Diameter & 1.33 & Diameter & 0.95 \\
& & Pitch & 1.26 \\
$\mathrm{~h} / \mathrm{G}$ & 0.75 & G (rod-rod gap) & 0.31 \\
& & h (rod-wall gap) & 0.23 \\
$\mathrm{q}_{\text {peak }} / \mathrm{q}_{\text {avg }}$ & 1.5 & Channel Width & 2.67 \\
\hline
\end{tabular}

Due to concerns that boiling and flow induced vibrations would potentially cause the heaters to make contact and significantly alter the geometry, three small and sparsely located grid spacers were applied. The design used in the experiment yields a $16 \%$ flow blockage of a length of $2.54 \mathrm{~cm}$ per spacer and do not have mixing vanes. The three spacers used in this study were centered at $1.0,1.5$, and $\sim 2.0 \mathrm{~m}$ as measured from the upstream end of the heated section of the heater elements (Figure 4).

Standard practices of CHF detection employs thermocouples located at various locations either on the outer or inner wall of the heater's cladding [6]. In this study, ten thermocouples per heater are embedded on the inner wall of the cladding in each heater element at different axial and circumferential positions (Figure 4). The positions of the thermocouples were chosen to maximize detection of first CHF occurrence. Additional thermocouples monitored the inlet, outlet, and bulk fluid temperatures within the channel.
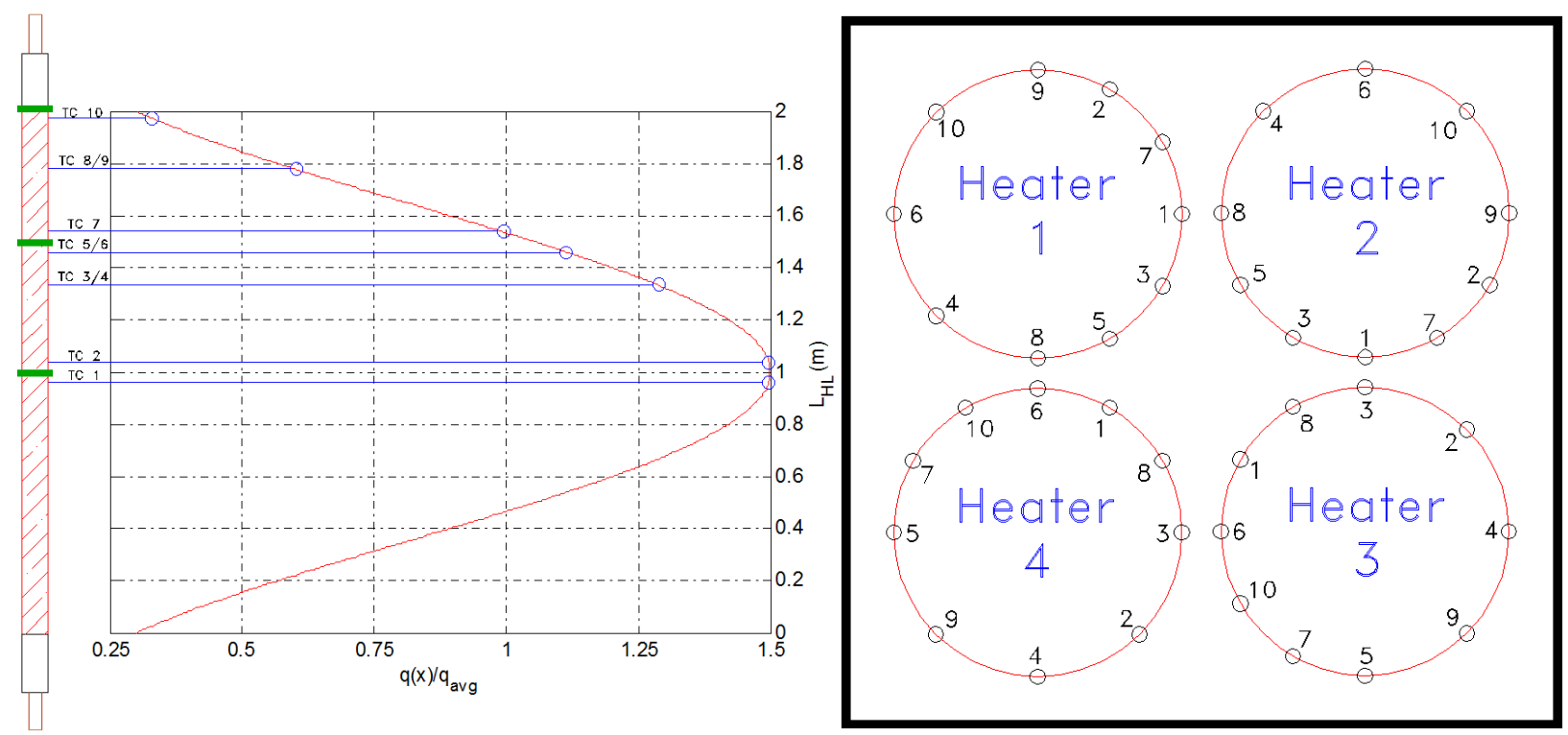

Figure 4. (Left) Axial thermocouple location, heater profile, and spacer locations (green markers). (Right) Circumferential thermocouple locations. 


\subsection{Experimental Procedure}

From a steady state condition, the power of the heater elements is increased slowly ( 1 $\mathrm{kW} /$ heater/min). As the power level increases, the system pressure is allowed to rise as the inlet subcooling is controlled. Additionally, the mass flux is adjusted to maintain a constant mass flux or allowed to slightly decrease. The facility is thus brought to a critical condition where a CHF event w occur, recognizable by a significant spike (Figure 5) in one or more of the thermocouples embedded in the heater elements. This procedure is a common method for obtaining experimental CHF data [7].

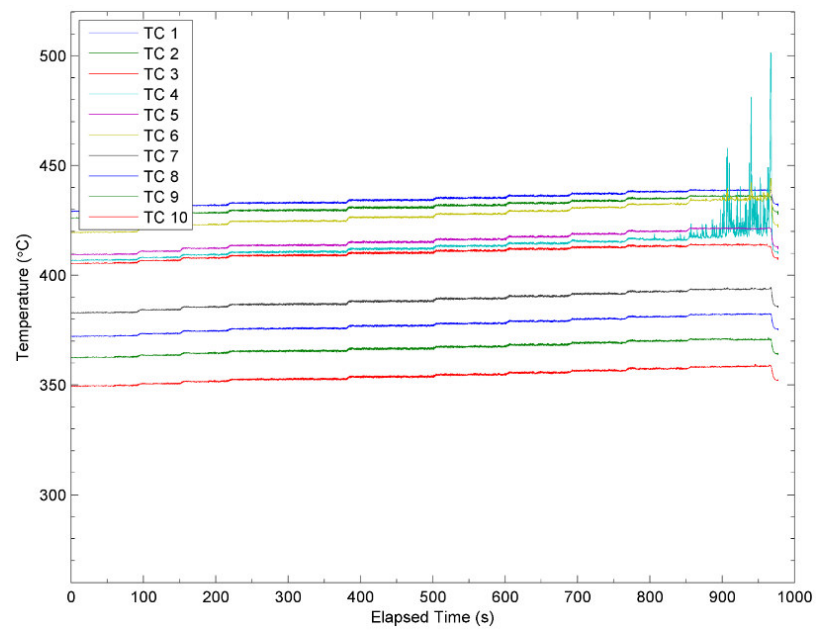

Figure 5. Characteristic heater element thermocouple response to a CHF event

The 'trip' temperature for the system which indicates $\mathrm{CHF}$ occurrence is set approximately $150^{\circ} \mathrm{C}$ above the saturation point (i.e. $\sim 75-100^{\circ} \mathrm{C}$ above the embedded thermocouple measurements). Once the $\mathrm{CHF}$ event is detected, the power is automatically reduced and a steady state condition is established. The process is then repeated. This $150^{\circ} \mathrm{C}$ threshold, while arbitrary, does not significantly alter the measured $\mathrm{CHF}$ point and associated system conditions due to the slow approach to the $\mathrm{CHF}$ and magnitude of the temperature excursion. Using this procedure, a total of $96 \mathrm{CHF}$ tests have been performed covering the inlet conditions outlined in Table II. The full test summary can be found in Appendix A and reference [5].

Table II. Summary of inlet conditions of CHF data

\begin{tabular}{cc}
\hline Parameter & Range \\
\hline Inlet Subcooling $(\mathrm{kJ} / \mathrm{kg})-\mathrm{h}_{\text {sub }}$ & $250-650$ \\
Inlet Pressure $(\mathrm{MPa})-\mathrm{P}_{\text {in }}$ & $8-16$ \\
Mass Flux $\left(\mathrm{kg} / \mathrm{m}^{2} \mathrm{~s}\right)-\mathrm{G}$ & $500-1600$ \\
\hline
\end{tabular}

A representative distribution of the maximum error for any give test is presented in Table III. The primary sources of measurement error for these $\mathrm{CHF}$ tests are associated with $\mathrm{CHF}$ detection based on the thermocouple locations on the heater elements, voltage and current uncertainties of the heaters, 
inlet conditions (i.e. temperature and pressure), and mass flux through the test section (depends on multiple parameters). Using manufacture specified uncertainty, geometry tolerances, etc., the error associated with various parameters was calculated using propagation of error. The large error associated with the local CHF is dependent on the spacing between each individual heating element's thermocouples. The estimated heat lost in the test section is limited to a maximum of a few percent.

Table III. Summary of main parameter uncertainty from propagation of error analysis

\begin{tabular}{|c|c|c|c|c|}
\hline Parameter & Nominal Value & $\pm \sigma$ & Unit & $\%$ Error \\
\hline Inlet Subcooling & 409 & 13 & $\mathrm{~kJ} / \mathrm{kg}$ & $3.1 \%$ \\
\hline Inlet Pressure & 12.1 & 0.16 & $\mathrm{MPa}$ & $1.3 \%$ \\
\hline Mass Flux & 898 & 17 & $\mathrm{~kg} / \mathrm{m}^{2} \mathrm{~s}$ & $1.9 \%$ \\
\hline Heater Power & 56.0 & 0.79 & $\mathrm{~kW}$ & $1.4 \%$ \\
\hline $\begin{array}{c}\text { Average Critical } \\
\text { Heat Flux }\end{array}$ & 930 & 16 & $\mathrm{~kW} / \mathrm{m}^{2}$ & $1.7 \%$ \\
\hline $\begin{array}{l}\text { Local Critical } \\
\text { Heat Flux }\end{array}$ & 1250 & 200 & $\mathrm{~kW} / \mathrm{m}^{2}$ & $16 \%$ \\
\hline \multicolumn{5}{|c|}{$\left(\frac{\delta x}{\delta a} \sigma_{a}\right)^{2}+\left(\frac{\delta x}{\delta b} \sigma_{b}\right)^{2}+\left(\frac{\delta x}{\delta c} \sigma_{c}\right)^{2}$} \\
\hline
\end{tabular}

\section{CRITICAL HEAT FLUX DATA}

The following section presents CHF data gathered from the HPCHF facility according to important parameters commonly evaluated in discussions of the CHF from a fixed inlet condition approach. The primary variables under consideration are those summarized in Table II; namely inlet subcooling, inlet pressure, mass flux, and exit quality. For reference, the local and average CHF are defined by Equations 2 and 3 where $A_{h t d}$ is the heated area of a heater element, $D$ is the diameter of a heater element and $L_{H L}$ is the heated length, and the average and local heat flux $\left(q_{\text {avg }}^{\prime \prime}\right.$ and $\left.q_{\text {local }}^{\prime \prime}\right)$ have been defined with Equation 1. The complete experimental data set is included in Appendix A.

$$
\begin{aligned}
& q_{\text {avg }}^{\prime \prime}=\frac{q_{\text {avg }}}{A_{\text {htd }}} ; q_{\text {local }}^{\prime \prime}=\frac{q(x)}{A_{h t d}} \\
& A_{\text {htd }}=\pi \times D \times L_{H L}
\end{aligned}
$$

In order to better visualize the conditions covered by the experimental data in context of existing literature Figure 6 and Figure 7 are presented below. These figures are the same EPRI plots presented in the introduction with the addition of this reports experimental data. 

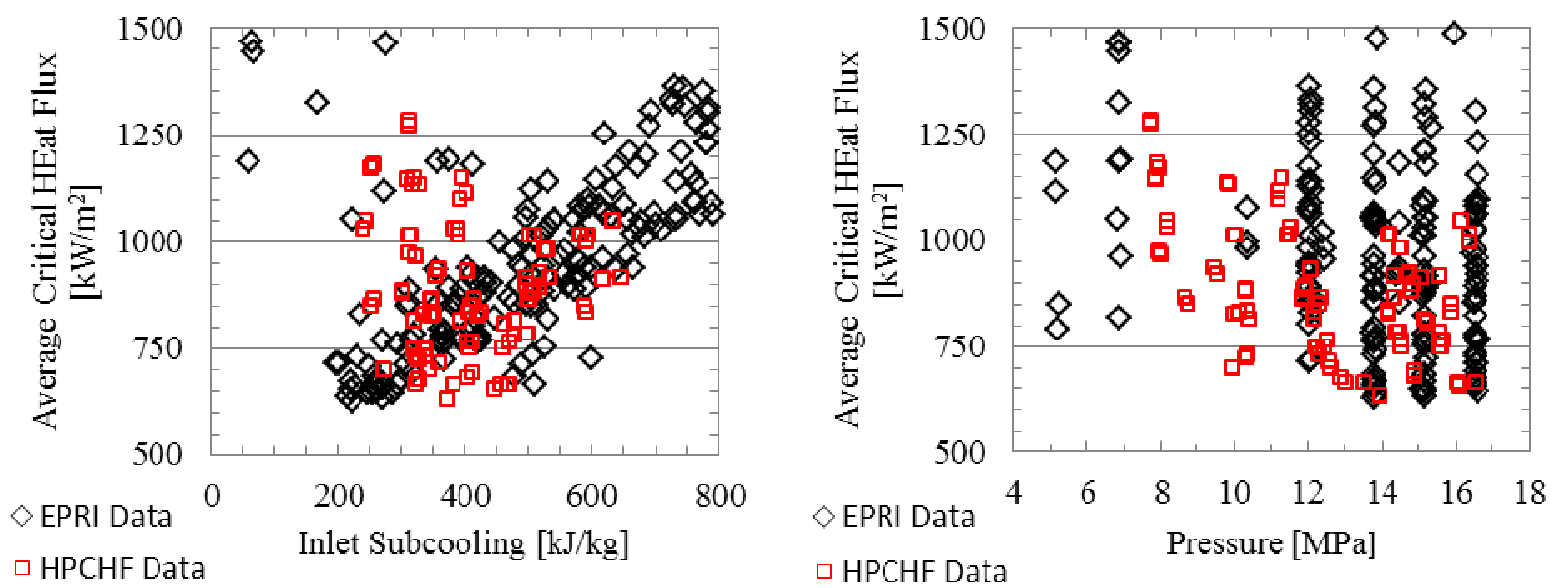

Figure 6. Overlay of experimental data and EPRI data for non-uniform heat fluxes, $P<17$ [MPa], and G $<1700[\mathrm{~kg} / \mathrm{m} 2 \mathrm{~s}]$.

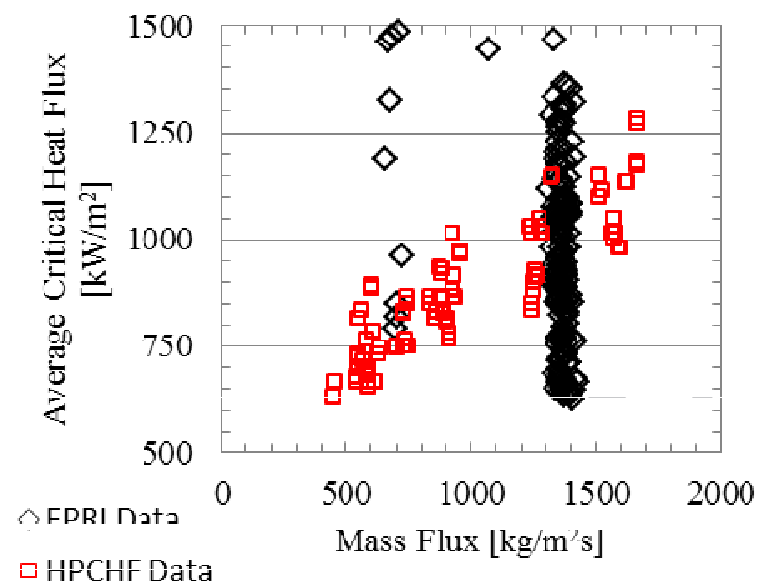

Figure 7. Overlay of experimental data and EPRI data for non-uniform heat fluxes, $P<17$ [MPa], and G $<1700[\mathrm{~kg} / \mathrm{m} 2 \mathrm{~s}]$.

Figure 8 illustrates the locations and number of $\mathrm{CHF}$ occurrences registered at each thermocouple. There are 115 indicated CHF events in the figure out of 96 tests due to simultaneous trip of multiple thermocouples on a few tests (typically between thermocouples at the same axial position). It was anticipated that the most likely axial heights for CHF were to be at thermocouples 3/4, 5/6, and/or 7 based on behavior of a non-uniform power profile. Circumferentially, it was reasoned that rod-rod gaps, rod-wall gaps, and the center channel were to be the most likely locations of CHF given proximity of heaters and flow restrictions. Although rare that multiple thermocouples were tripped that were not at the same vertical location ( 3 occurrences), when it did occur, the local CHF value was determined from the tripped thermocouple located most upstream (higher local CHF value). This does not significantly impact the results of local CHF presented in Table IV. 
With these prior predictions, the map of $\mathrm{CHF}$ in Figure 8 seems to match assumptions. The locations of the thermocouples on heaters 3 and 4 are more strategically oriented than of heaters 1 or 2 (i.e. thermocouples are located at both axial and circumferential locations matching the previously mentioned expected CHF locations). Therefore, although the tripped thermocouples are mostly located on heaters 3 and 4 , the locations of the thermocouples tripped are in the areas believed to be most conducive for a CHF event and not necessarily indicative of significant deviations of non-uniformity in subchannel properties. Furthermore, as the CHF condition in any given test was approached, typically multiple perturbations in heater thermocouples were observed and a set of four bulk thermocouples, located at the same axial location $(1.78 \mathrm{~m})$ and near the wall between each set of heaters, were typically in agreement adding some qualitative support to that conclusion. Therefore, a CHF location map such as Figure 8 appears to not be uncommon or unreasonable given similar maps reported in literature [8] and the previous discussion.

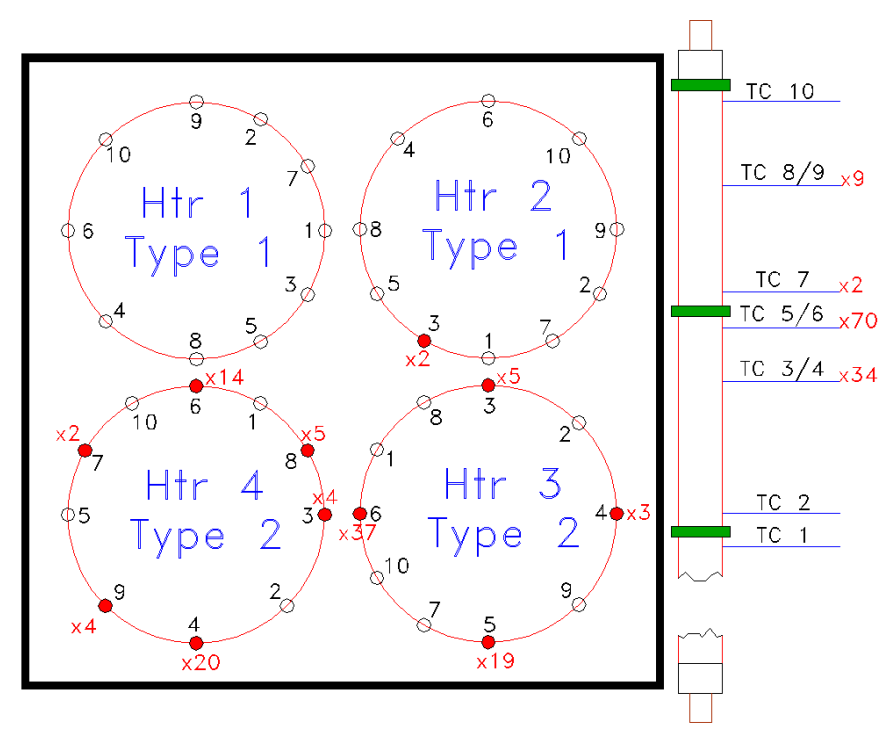

Figure 8. Location of CHF occurrence detected with embedded thermocouples

\subsection{Influence of Parameters: Subcooling, Pressure, Mass Flux, and Exit Quality}

Within the range of experimental conditions covered in this study, open literature predicts a linear behavior between CHF and inlet subcooling [9]. In other words, the change of the CHF value is directly proportional to the energy required to obtain a saturated condition given all other variables remain constant. Evaluation of the data in this regard demonstrates that the expected trend of a linear increase in the CHF with increasing subcooling is indeed observed (Figure 9 - Left). Note, all lines in Figure 9 and Figure 10 are to assist in trend visualization and are not necessarily an indication of a linear correlation. Furthermore, the portions of data plotted below have been grouped together whose conditions are within $\sim+-5 \%$ of the specified values in the legend.

Pressure has a complicated effect on the CHF. For a fixed inlet approach, as pressure is increased, the $\mathrm{CHF}$ will increase, reach a maximum, and then decrease. Readers are directed to other sources such as [10] for possible explanations of this behavior though in essence it is thought to be highly dependent on 
the physical properties of water and their impact on flow behavior. Given that the experimental data of this study lies at higher pressures, $\mathrm{CHF}$ is expected to decrease as the pressure increases. Figure 9 (Right) presents the CHF data as a function of the inlet pressure. This figure demonstrates a clear decrease in the $\mathrm{CHF}$ with increasing pressure as expected.
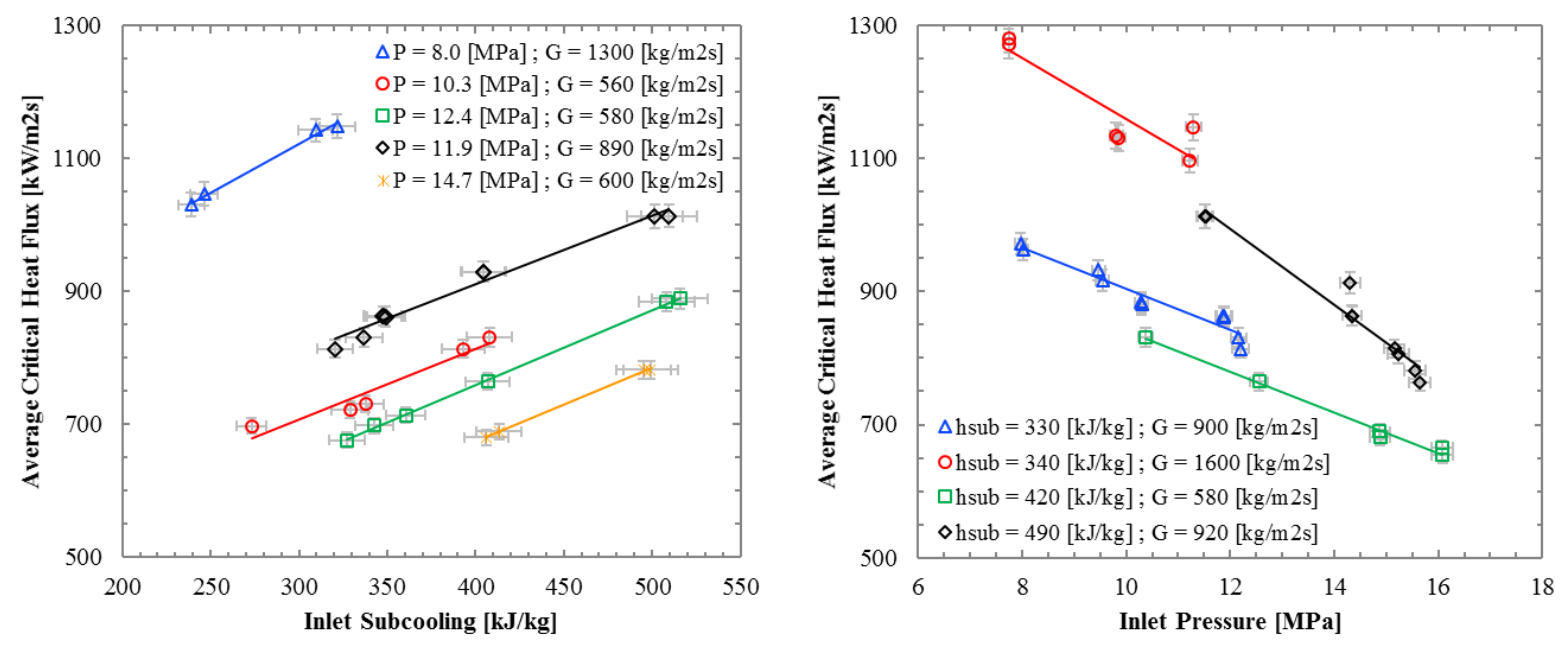

Figure 9. (Left) CHF vs. Inlet Subcooling with linearly increasing correlation. (Right) CHF vs. Pressure with clear decrease in CHF with increasing pressure.

Similar to inlet subcooling, the CHF has been shown to increase with increasing mass flux in a quasi linear behavior. This dependency is generally greater at lower flow mass fluxes and diminishes at higher pressures, presumably dependent on the change of flow patterns [11]. Once again for the conditions at which experiments were run, the expected monotonically increasing behavior of mass flux and CHF was observed (Figure 10 - Left). Exit quality conversely has been shown to increase with decreasing mass flux [11] with which this experimental data is in agreement (Figure 10-Right). Exit quality in the plot is not a measured value, rather it is simple calculation using a heat balance based on the inlet conditions and heater element powers with no energy losses. 

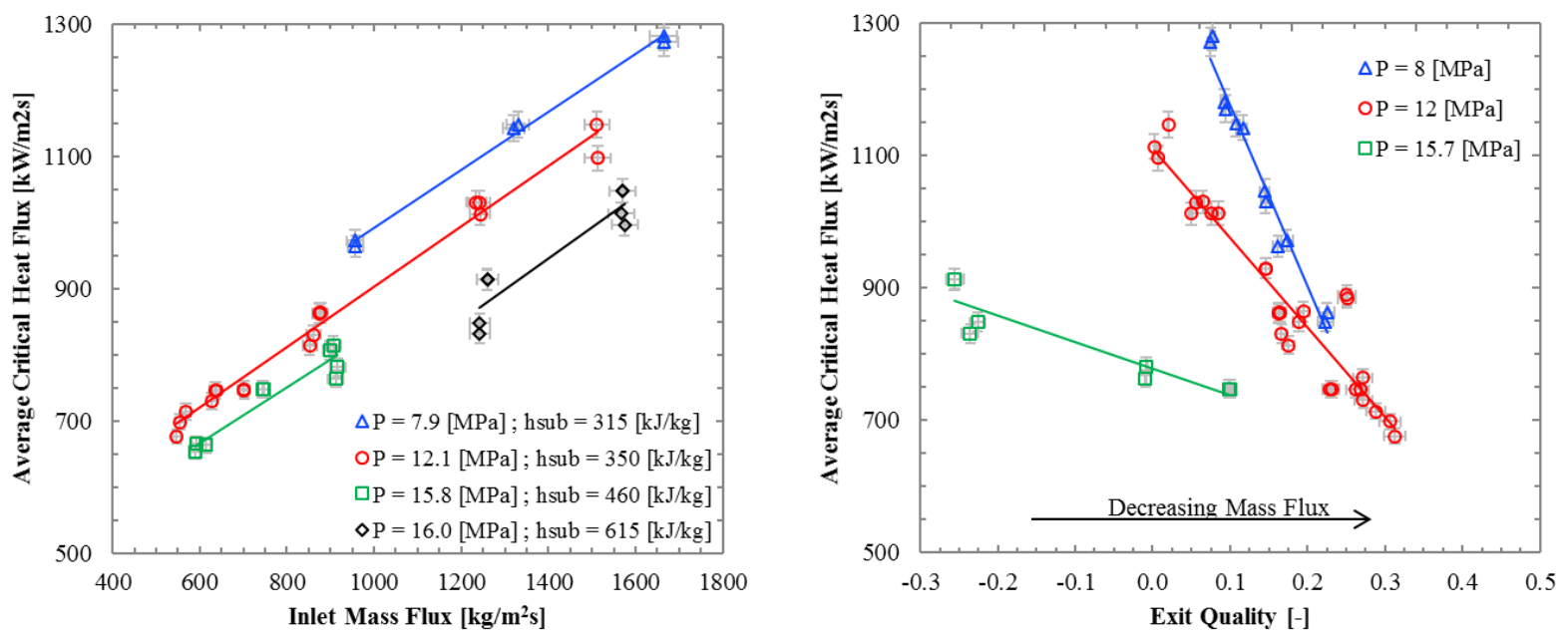

Figure 10. (Left) CHF vs. Mass Flux with monotonic increase of the CHF with increasing mass flux. (Right) CHF vs. Exit Quality with decrease in CHF with increase in quality.

\subsection{Comparison to CHF Correlations}

Chosen for their wide acceptance and validated range of applicability similar to this study, the EPRI correlation (with the non-uniform correction and cold wall factors but not the grid spacer factor) [12], the CISE-GE [13], the W-3 (with the non-uniform correction factor) [14], and the 2006 Groeneveld LookUp-Table (LUT) (with correction factors 1, 2, 4, and 5) [15] have been selected for comparison to experimental data. It is worth noting that each prediction was evaluated with various combinations of their correction factors, where applicable. The correlations with the specified factors indicated in Table IV produced the most accurate results based on the mean and RMS error of the average CHF.

In addition to the generalized prediction methods, an Artificial Neural Network (ANN) analysis using MATLAB's 'neural net fitting tool' was also employed using a random subset of $70 \%$ of the experimental data to 'train' the network. An ANN applies statistical learning algorithms inspired by biological neural networks (i.e. central nervous system). It is ideal for pattern recognition and is an alternative way to tackle complex and ill-defined problems (i.e. CHF appears to be a perfect candidate). For brevity the interested reader is directed to these references [16] [17] [18] [19] for a more thorough discussion of ANN and its successful application to CHF. The error presented in Table IV for ANN represents only the mean/error associated with data not used in training and is less accurate (i.e. more realistic) of the ANN prediction capabilities for this data set. The network used has three inputs: inlet subcooling, inlet pressure, and mass flux; one output: local or average CHF; and one hidden layer with five neurons.

Based on the common approach of channel centered flow geometries in subchannel analysis and its more consistent accuracy (in terms of average critical heat flux), the prediction results were calculated from the channel centered approach (Figure 11 - Left). Using this geometry and the primary inlet conditions, the iterative heat balance method (HBM) [15] was used to determine the predicted location of CHF. The HBM iteratively increases the overall heater power until local heater flux and predicted CHF are within a specified tolerance of one another. The predicted local heat flux is the flux associated with 
the convergence location. The average $\mathrm{CHF}$ is calculated based on the value of the total heater power at convergence. This process is conceptually captured below with a representative iteration depicted in the right image of Figure 11.
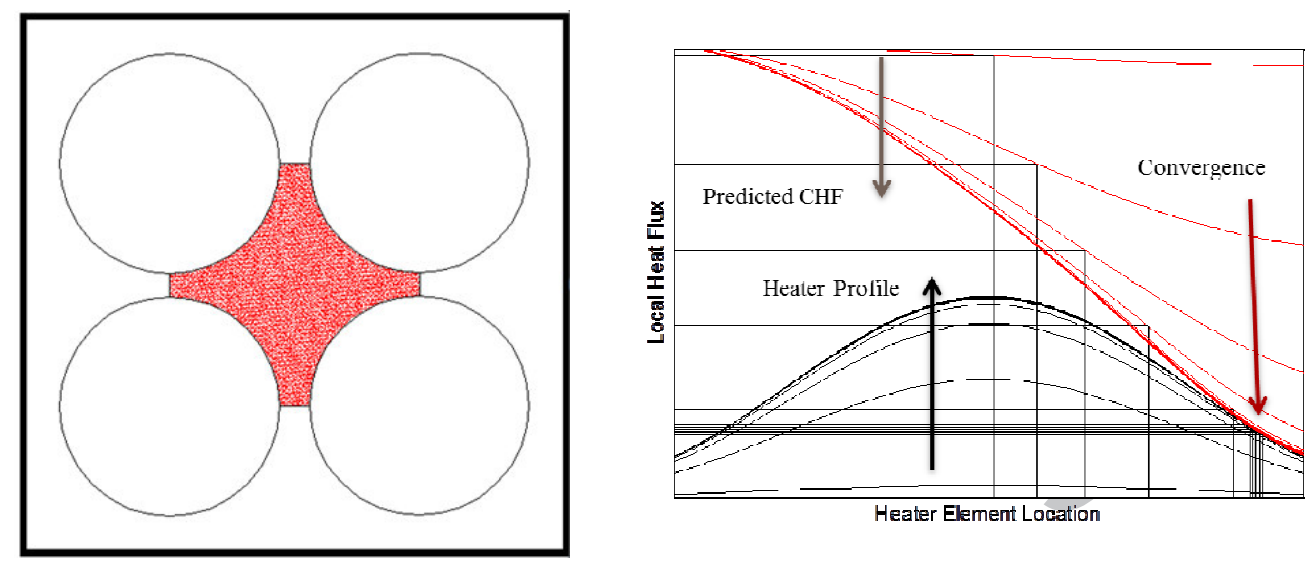

Figure 11. (Left) Channel centered flow geometry marked in red. (Right) Iterative HBM example.

The comparison between the prediction methods and experimental data is shown graphically in Figure 12 with an associated error summary presented in Table IV. In general the EPRI, the CISE-GE, and the W3 all predict the average CHF reasonably with means relatively near $0 \%$ and RMS errors not too divergent from the reported prediction accuracies of approximately $10-20 \%$. The notable difference is tendency of the EPRI and CISE to predict conservative CHF values while the $\mathrm{W}-3$ and 2006 LUT error on the side of being non-conservative (over predicts the $\mathrm{CHF}$ ). It is noted that each of the correlations have regions of both over and under predicting the $\mathrm{CHF}$ which should not be overlooked. Furthermore, the non-conservative 2006 LUT (based on heated $8 \mathrm{~mm}$ tubes) performance could be a result of cold wall effects not explicitly handled by a correction factor unlike the EPRI which has an explicit cold wall factor that lowers the predicted CHF by $\sim 5-10 \%$ for the conditions considered in this paper.

The performance of the ANN demonstrates the predictability of the facility behavior and helps to substantiate the confidence in the repeatability of the facility at the conditions tested. It is hypothesized that, similar to previous applications of ANN to $\mathrm{CHF}$, this network could be applied in overcoming limitations of the test facility and associated database in order to better understand CHF behavior at SMR conditions.

Although average $\mathrm{CHF}$ was relatively well represented, all correlations failed to provide reasonably accurate predictions of local CHF (i.e. CHF location occurrence). This is to be expected since there is significant uncertainty associated with the first occurrence of $\mathrm{CHF}$ given the limited number of heater thermocouples (Table III). If the location of CHF could be more precisely determined it is reasonable to suggest that the associated local CHF could be decreased. Therefore, the predicted vs real local CHF value is arguably in better agreement than that indicated in Table IV. 


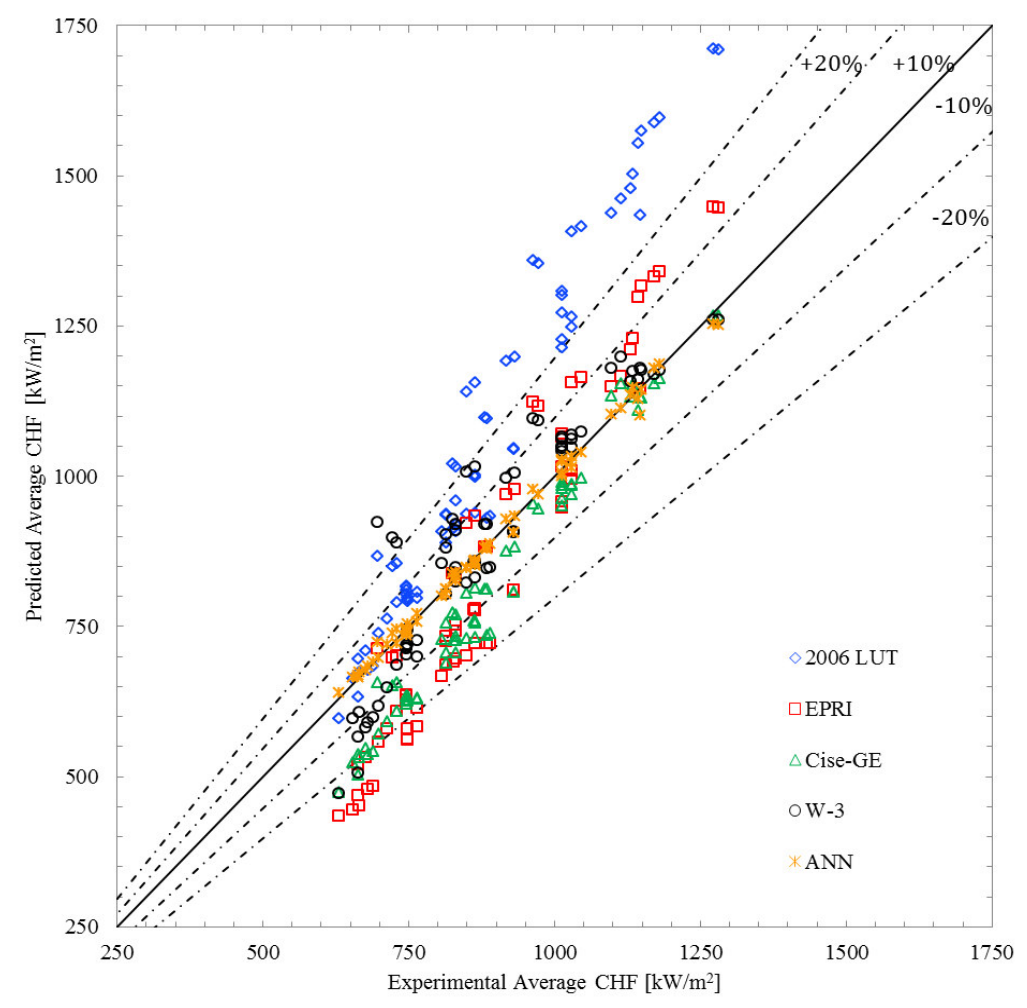

Figure 12. Comparison of average CHF prediction methods to experimental data

Table IV. Summary of local and average CHF prediction vs. experimental error

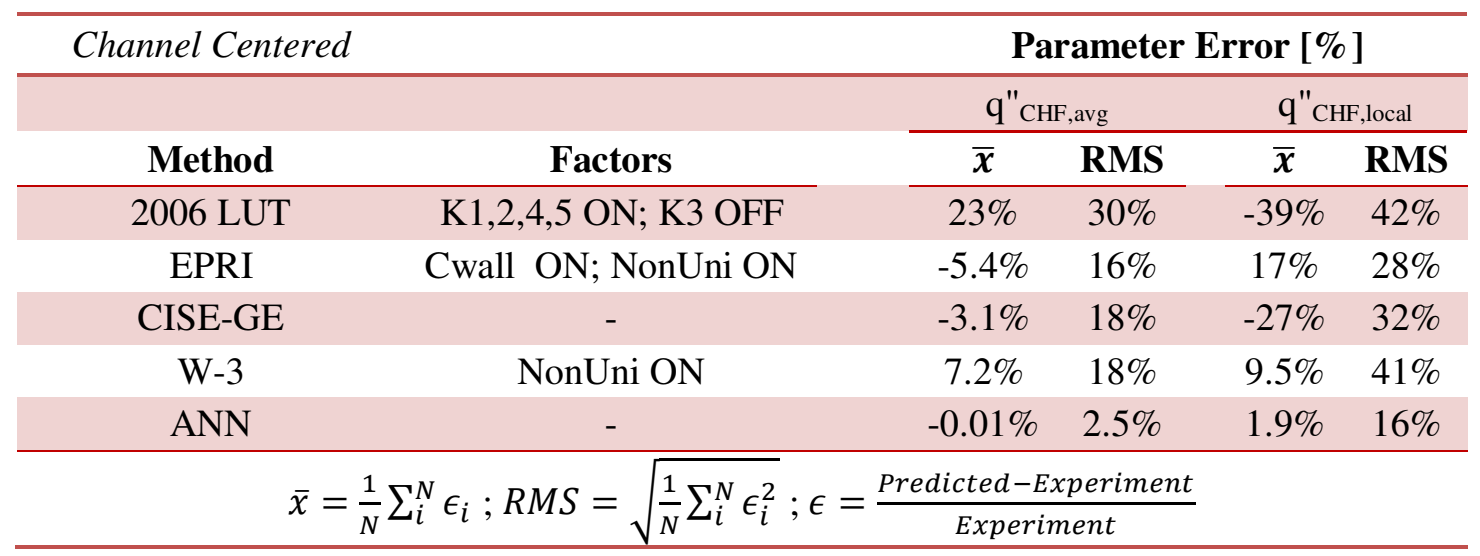

The predicted $\mathrm{CHF}$ deviation from experimental results $(\varepsilon)$ for the four primary parameters discussed are shown in Figure 13 and Figure 14. Although some correlations were able to predict the average CHF for these conditions, these figures show a bias of these methods compared to the experimental data. One reason for this bias is the non-complete independence between the inlet parameters (inlet subcooling, pressure, and mass flux) as discussed in Section 2.3. On the other hand, the ANN is presented as a regression model able to predict the average $\mathrm{CHF}$ with errors normally distributed around zero (considering only the values not used for training the network). An application of an ANN in this sort of 
representation may be better suited to overcome a database's deficiencies and capture truly independent parameter deviations more accurately.
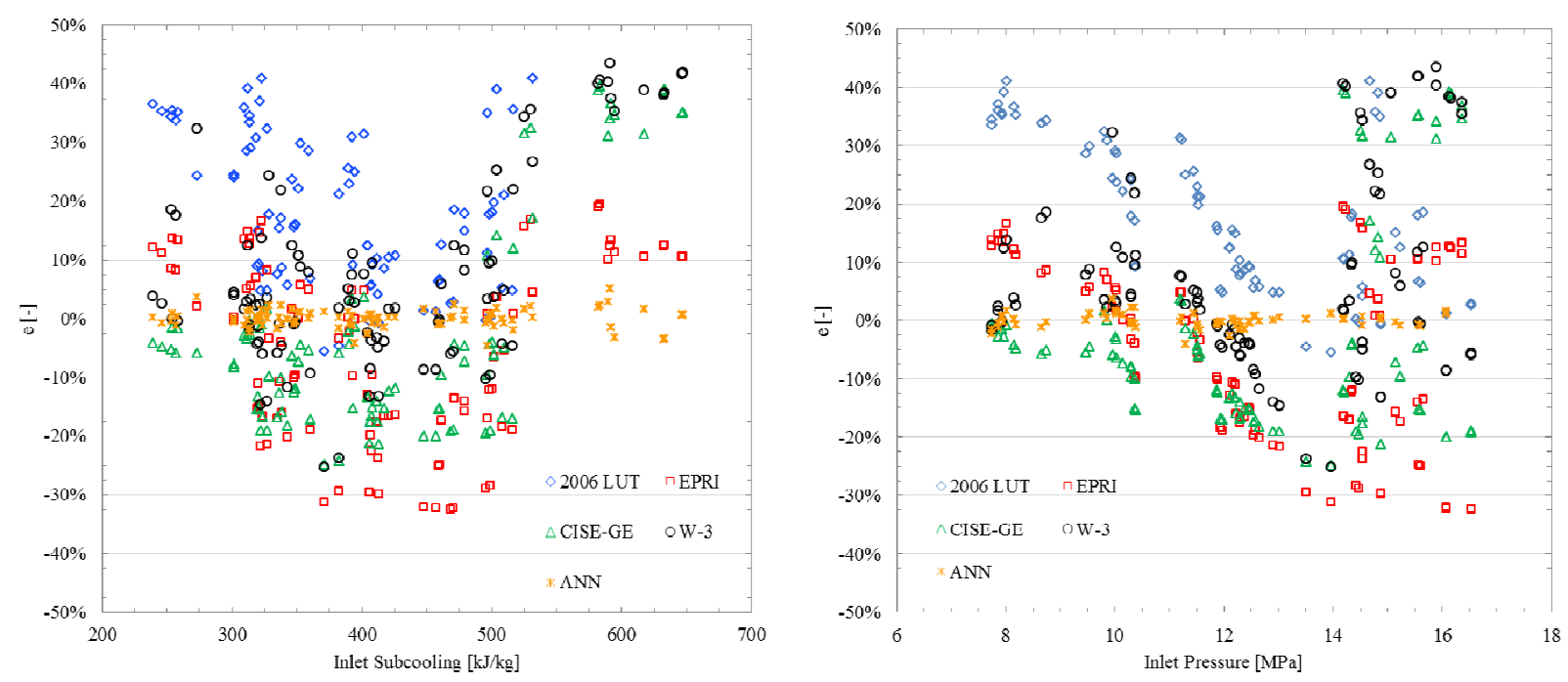

Figure 13. Prediction relative error as a function of (Left) inlet subcooling and (Right) pressure
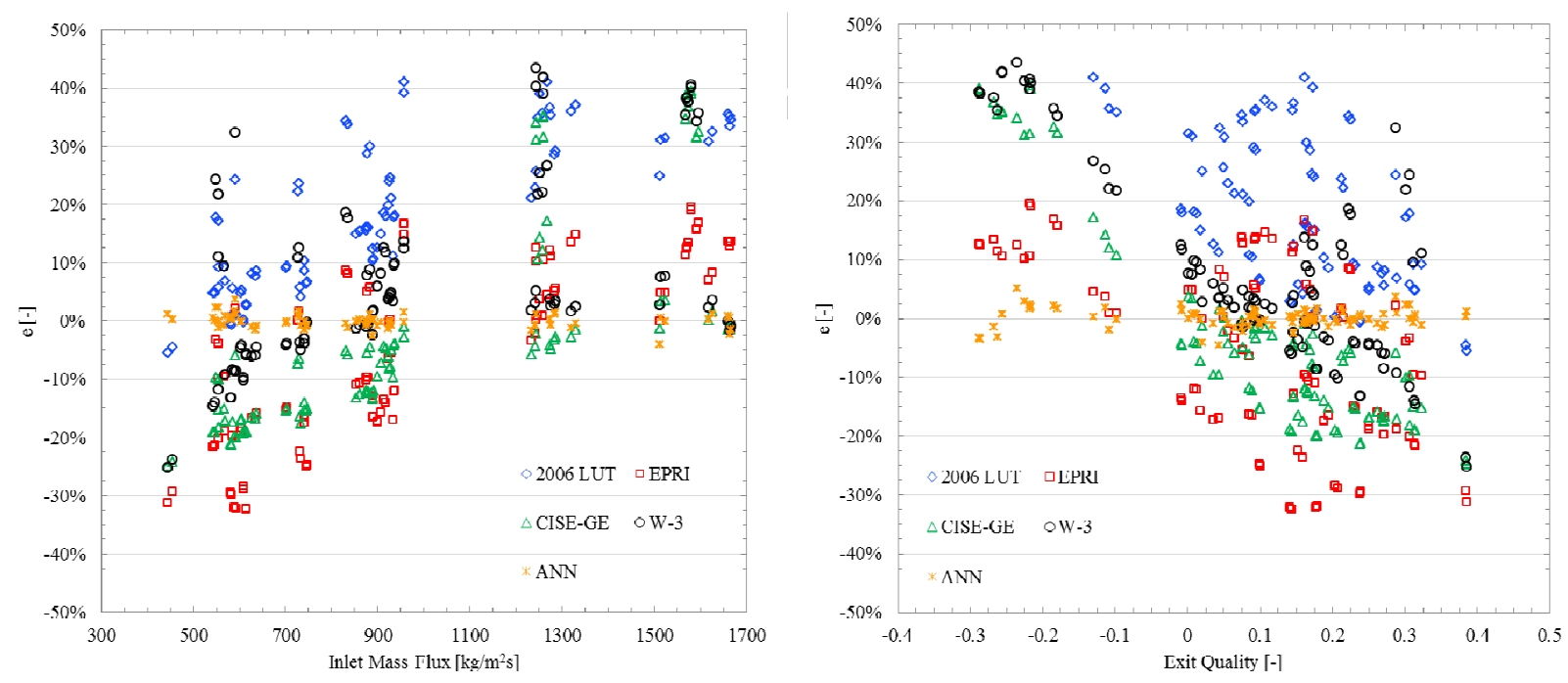

Figure 14. Prediction relative error as a function of (Left) mass flux and (Right) exit quality

\subsection{Scaling Critical Heat Flux Results}

Extrapolation of small bundle CHF experiments (e.g., 2x2) to larger commercial bundles (e.g., 17x17) remains an area of open research. This issue is not unique to this experiment as much literature experimental data is performed on scaled down facilities of varying bundle sizes (e.g., $5 \times 5,3 \times 3$ ) or even single heated elements (e.g., externally heated pipe or single elements enclosed in a non-heated pipe). It is likely that correlations that explicitly consider heated and non-heated parameters (e.g., surface/flow areas and channel geometry) and are created from data sets with different bundle sizes are more 
accurate over larger application ranges. For example, the reasonably good prediction by EPRI correlation on this data set may be attributable, in part, to the correlations consideration of cold wall effects and the fact the correlation is based on various sized heating element bundles.

This discussion provides additional motivation to investigate the application of computer learning to the study of CHF. The traditional approach to CHF prediction (i.e., correlation creation) relies on the skill of the scientist to predict the applicable physics and then manipulate the data to determine the weight or importance of the identified physics. This is a difficult task for similar data sets and even more so for more advanced applications. A computer learning approach may potentially enable far more accurate and more diverse prediction capabilities that will be able to address issues such as those of scaling laws discussed here. As such, a detailed study to understand the scaling laws of CHF experiments (e.g., single element $->2 \times 2->5 \times 5->17 \times 17$ ) is a potential area of further research.

\section{CONCLUSIONS}

Critical heat flux experiments have been conducted at the low mass flux and moderate to high pressure conditions prototypic of proposed light water SMR designs at the University of Wisconsin High Pressure Critical Heat Flux facility. This study contributes valuable CHF data spanning the conditions indicated in Table II, specifically in a $2 \times 2$ bundle configuration, for which minimal public data exists.

An investigation of the primary parameters demonstrated that expected trends in inlet subcooling, pressure, mass flux, and exit quality were observed. Comparison of the experimental data to prediction methods demonstrates the reasonably accurate prediction capabilities of the W-3, CISE-G, and EPRI correlations in regards to the average CHF. It is noted though that all prediction methods evaluated performed unsatisfactorily in regards to local CHF prediction, though a portion of that error is likely associated with the inherent limitation of thermocouple spacing by which local CHF was determined.

Finally, a neural network analysis was also performed on the experimental data which was capable of accurately predicting the experimental data, thereby demonstrating the predictability of the facility's behavior. Given the good performance of the ANN, it is possible that a well-trained ANN can be a useful tool in overcoming experimental and database limitations to expand understanding of $\mathrm{CHF}$ and, more generally, thermal hydraulics. A potential application of ANN is expanding the accuracy of predictions between small scale experiments and commercial scale facilities.

\section{ACKNOWLEDGMENTS}

This research was performed using funding received from the DOE Office of Nuclear Energy's Nuclear Energy University Programs. 
Appendix A: Complete Experimental Data Summary

\begin{tabular}{|c|c|c|c|c|c|c|c|c|c|}
\hline $\begin{array}{c}\text { Test } \\
\text { Number }\end{array}$ & $\begin{array}{c}\text { Inlet } \\
\text { Subcooling } \\
{[\mathrm{kJ} / \mathrm{kg}]}\end{array}$ & $\begin{array}{c}\text { Inlet } \\
\text { Pressure } \\
\text { [MPa] }\end{array}$ & $\begin{array}{c}\text { Mass } \\
\text { Flux } \\
{\left[\mathrm{kg} / \mathrm{m}^{2} \mathrm{~s}\right]}\end{array}$ & Tripped TC & $\begin{array}{c}\text { Local CHF } \\
\text { Location } \\
{[\mathrm{m}]}\end{array}$ & $\begin{array}{c}\text { Local } \\
\text { Quality } \\
{[-]}\end{array}$ & $\begin{array}{c}\text { Exit } \\
\text { Quality } \\
\text { [-] }\end{array}$ & $\begin{array}{l}q^{\prime \prime} \mathrm{CHF}, \text { local } \\
{\left[\mathrm{kW} / \mathrm{m}^{2}\right]}\end{array}$ & $\begin{array}{l}q^{\prime \prime}{ }_{C H F, a v g} \\
{\left[\mathrm{~kW} / \mathrm{m}^{2}\right]}\end{array}$ \\
\hline Test 1 & 329 & 10.3 & 549 & Htr 3 TC 6 & 1.46 & 0.20 & 0.31 & 808 & 722 \\
\hline Test 2 & 338 & 10.4 & 554 & Htr 3 TC 6 & 1.46 & 0.20 & 0.30 & 818 & 730 \\
\hline Test 3 & 346 & 10.0 & 728 & Htr 3 TC 6 & 1.46 & 0.12 & 0.21 & 924 & 825 \\
\hline Test 4 & 351 & 10.2 & 727 & Htr 3 TC 6 & 1.46 & 0.12 & 0.21 & 931 & 831 \\
\hline Test 5 & 359 & 9.5 & 877 & Htr 3 TC 6 & 1.46 & 0.09 & 0.17 & 1044 & 932 \\
\hline Test 6 & 353 & 9.5 & 884 & Htr 3 TC 6 & 1.46 & 0.08 & 0.16 & 1027 & 917 \\
\hline Test 7 & 407 & 12.6 & 586 & Htr 3 TC 6 & 1.46 & 0.15 & 0.27 & 857 & 765 \\
\hline Test 8 & 412 & 12.3 & 740 & Htr 3 TC 5 & 1.46 & 0.09 & 0.19 & 951 & 849 \\
\hline Test 9 & 417 & 12.4 & 741 & Htr 3 TC 6 & 1.46 & 0.09 & 0.19 & 968 & 864 \\
\hline Test 10 & 405 & 12.1 & 889 & $\mathrm{Htr} 3 \mathrm{TC} 6$ & 1.46 & 0.05 & 0.15 & 1042 & 930 \\
\hline Test 11 & 404 & 12.1 & 890 & Htr 3 TC 6 & 1.46 & 0.05 & 0.15 & 1042 & 930 \\
\hline Test 12 & 322 & 13.0 & 542 & Htr 4 TC 4 & 1.33 & 0.15 & 0.31 & 859 & 664 \\
\hline Test 13 & 327 & 12.9 & 547 & Htr 4 TC 4 & 1.33 & 0.15 & 0.31 & 875 & 676 \\
\hline Test 14 & 319 & 12.5 & 702 & Htr 3 TC 6 & 1.46 & 0.14 & 0.23 & 838 & 747 \\
\hline Test 15 & 321 & 12.5 & 702 & Htr 4 TC 4 & 1.33 & 0.10 & 0.23 & 966 & 747 \\
\hline Test 16 & 337 & 12.2 & 860 & Htr 4 TC 4 & 1.33 & 0.05 & 0.17 & 1074 & 831 \\
\hline Test 17 & 320 & 12.2 & 852 & Htr 4 TC 4 & 1.33 & 0.06 & 0.18 & 1053 & 814 \\
\hline Test 18 & 413 & 14.9 & 584 & Htr 4 TC 4 & 1.33 & 0.07 & 0.24 & 892 & 689 \\
\hline Test $19 *$ & 406 & 14.9 & 581 & Htr 4 TC 8 & 1.78 & 0.21 & 0.24 & 417 & 681 \\
\hline Test $20^{*}$ & 412 & 14.5 & 734 & Htr 4 TC 7 & 1.54 & 0.08 & 0.16 & 767 & 764 \\
\hline Test 21 & 408 & 14.5 & 731 & Htr 3 TC 5 & 1.46 & 0.05 & 0.15 & 838 & 748 \\
\hline Test 22 & 426 & 14.2 & 892 & Htr 3 TC 5 & 1.46 & -0.01 & 0.09 & 932 & 832 \\
\hline Test 23 & 421 & 14.2 & 889 & Htr 3 TC 5 & 1.46 & 0.00 & 0.09 & 927 & 827 \\
\hline Test $24^{*}$ & 457 & 16.1 & 592 & Htr 4 TC 8 & 1.78 & 0.14 & 0.18 & 408 & 665 \\
\hline Test 25 & 448 & 16.1 & 589 & $\mathrm{Htr} 4 \mathrm{TC} 7$ & 1.54 & 0.08 & 0.18 & 656 & 654 \\
\hline Test 26 & 459 & 15.6 & 745 & Htr 3 TC 5 & 1.46 & -0.01 & 0.10 & 838 & 748 \\
\hline Test $27^{*}$ & 460 & 15.6 & 746 & Htr 4 TC 8 & 1.78 & 0.07 & 0.10 & 458 & 748 \\
\hline Test 28 & 479 & 15.2 & 907 & Htr 3 TC 5 & 1.46 & -0.08 & 0.02 & 913 & 814 \\
\hline Test 29 & 462 & 15.2 & 899 & Htr 3 TC 5 & 1.46 & -0.06 & 0.03 & 904 & 807 \\
\hline Test 30 & 360 & 12.6 & 568 & Htr 4 TC 4 & 1.33 & 0.13 & 0.29 & 923 & 714 \\
\hline Test 31 & 343 & 12.6 & 555 & Htr 4 TC 4 & 1.33 & 0.15 & 0.31 & 903 & 698 \\
\hline Test $32 *$ & 383 & 13.5 & 456 & Htr 3 TC 4 & 1.33 & 0.19 & 0.38 & 858 & 664 \\
\hline Test 33* & 371 & 14.0 & 445 & Htr 3 TC 4 & 1.33 & 0.19 & 0.39 & 817 & 631 \\
\hline Test 34 & 339 & 12.2 & 638 & Htr 4 TC 4 & 1.33 & 0.12 & 0.26 & 966 & 747 \\
\hline Test 35 & 335 & 12.3 & 635 & Htr 3 TC 6 & 1.46 & 0.16 & 0.27 & 837 & 747 \\
\hline
\end{tabular}




\begin{tabular}{|c|c|c|c|c|c|c|c|c|c|}
\hline $\begin{array}{c}\text { Test } \\
\text { Number }\end{array}$ & $\begin{array}{c}\text { Inlet } \\
\text { Subcooling } \\
{[\mathrm{kJ} / \mathrm{kg}]}\end{array}$ & $\begin{array}{c}\text { Inlet } \\
\text { Pressure } \\
\text { [MPa] }\end{array}$ & $\begin{array}{c}\text { Mass } \\
\text { Flux } \\
{\left[\mathrm{kg} / \mathrm{m}^{2} \mathrm{~s}\right]}\end{array}$ & Tripped TC & $\begin{array}{c}\text { Local CHF } \\
\text { Location } \\
{[\mathrm{m}]}\end{array}$ & $\begin{array}{c}\text { Local } \\
\text { Quality [- } \\
\text { ] }\end{array}$ & $\begin{array}{c}\text { Exit } \\
\text { Quality [- } \\
\text { ] }\end{array}$ & $\begin{array}{l}q^{\prime \prime} \mathrm{CHF}, \text { local } \\
{\left[\mathrm{kW} / \mathrm{m}^{2}\right]}\end{array}$ & $\begin{array}{l}q^{\prime \prime} \mathrm{cHF}, \mathrm{avg} \\
{\left[\mathrm{kW} / \mathrm{m}^{2}\right]}\end{array}$ \\
\hline Test 36 & 324 & 12.3 & 628 & Htr 3 TC 6 & 1.46 & 0.17 & 0.27 & 819 & 730 \\
\hline Test $37^{*}$ & 348 & 11.9 & 874 & Htr 3 TC 5 & 1.46 & 0.08 & 0.17 & 967 & 863 \\
\hline Test 38 & 349 & 11.9 & 876 & $\mathrm{Htr} 3 \mathrm{TC} 5$ & 1.46 & 0.08 & 0.16 & 966 & 862 \\
\hline Test 39 & 348 & 11.9 & 878 & $\mathrm{Htr} 4 \mathrm{TC} 4$ & 1.33 & 0.04 & 0.16 & 1117 & 863 \\
\hline Test 40 & 395 & 11.3 & 1511 & $\mathrm{Htr} 4 \mathrm{TC} 4$ & 1.33 & -0.07 & 0.02 & 1484 & 1148 \\
\hline Test 41 & 402 & 11.2 & 1523 & Htr 3 TC 6 & 1.46 & -0.06 & 0.00 & 1247 & 1113 \\
\hline Test 42 & 392 & 11.2 & 1513 & Htr 3 TC 6 & 1.46 & -0.05 & 0.01 & 1229 & 1097 \\
\hline Test 43 & 390 & 11.4 & 1243 & Htr 3 TC 5 & 1.46 & -0.02 & 0.05 & 1135 & 1013 \\
\hline Test 44 & 390 & 11.5 & 1241 & $\mathrm{Htr} 3 \mathrm{TC} 5$ & 1.46 & -0.01 & 0.06 & 1154 & 1030 \\
\hline Test 45 & 383 & 11.6 & 1234 & Htr 3 TC 5 & 1.46 & -0.01 & 0.06 & 1154 & 1030 \\
\hline Test 46 & 508 & 11.9 & 605 & Htr 4 TC 4 & 1.33 & 0.07 & 0.25 & 1143 & 885 \\
\hline Test 47 & 516 & 12.0 & 603 & Htr 3 TC 6 & 1.46 & 0.12 & 0.25 & 996 & 890 \\
\hline Test $48^{*}$ & 509 & 11.5 & 929 & $\mathrm{Htr} 4 \mathrm{TC} 4$ & 1.33 & -0.05 & 0.08 & 1310 & 1013 \\
\hline Test 49 & 502 & 11.5 & 924 & $\mathrm{Htr} 4 \mathrm{TC} 4$ & 1.33 & -0.05 & 0.09 & 1309 & 1013 \\
\hline Test 50 & 393 & 10.4 & 555 & Htr 3 TC 6 & 1.46 & 0.21 & 0.32 & 911 & 814 \\
\hline Test 51 & 408 & 10.4 & 567 & Htr 3 TC 6 & 1.46 & 0.19 & 0.31 & 931 & 832 \\
\hline Test 52 & 302 & 10.3 & 926 & Htr 3 TC 6 & 1.46 & 0.10 & 0.17 & 991 & 884 \\
\hline Test 53 & 302 & 10.3 & 927 & Htr 3 TC 6 & 1.46 & 0.10 & 0.17 & 987 & 881 \\
\hline Test 54 & 314 & 10.0 & 1285 & $\mathrm{Htr} 4 \mathrm{TC} 4$ & 1.33 & 0.00 & 0.09 & 1309 & 1012 \\
\hline Test 55 & 312 & 10.0 & 1282 & $\mathrm{Htr} 4 \mathrm{TC} 4$ & 1.33 & 0.01 & 0.09 & 1309 & 1012 \\
\hline Test 56 & 327 & 9.8 & 1626 & $\mathrm{Htr} 4 \mathrm{TC} 4$ & 1.33 & -0.03 & 0.04 & 1467 & 1135 \\
\hline Test 57 & 319 & 9.9 & 1617 & $\mathrm{Htr} 4 \mathrm{TC} 4$ & 1.33 & -0.03 & 0.05 & 1463 & 1131 \\
\hline Test 58 & 273 & 10.0 & 591 & Htr 3 TC 6 & 1.46 & 0.19 & 0.29 & 781 & 697 \\
\hline Test 59 & 257 & 8.7 & 834 & Htr 3 TC 6 & 1.46 & 0.15 & 0.22 & 967 & 863 \\
\hline Test 60 & 253 & 8.7 & 832 & Htr 3 TC 6 & 1.46 & 0.15 & 0.22 & 951 & 849 \\
\hline Test 61 & 246 & 8.2 & 1275 & Htr 3 TC 6 & 1.46 & 0.09 & 0.14 & 1172 & 1047 \\
\hline Test 62 & 239 & 8.2 & 1273 & Htr 3 TC 6 & 1.46 & 0.09 & 0.15 & 1154 & 1030 \\
\hline Test 63 & 258 & 7.9 & 1664 & Htr 3 TC 6 & 1.46 & 0.04 & 0.09 & 1323 & 1181 \\
\hline Test 64 & 254 & 7.9 & 1660 & Htr 3 TC 6 & 1.46 & 0.04 & 0.09 & 1312 & 1171 \\
\hline Test 65 & 314 & 7.8 & 1664 & Htr 3 TC 6 & 1.46 & 0.02 & 0.08 & 1435 & 1282 \\
\hline Test 66 & 314 & 7.7 & 1665 & Htr 3 TC 6 & 1.46 & 0.02 & 0.07 & 1425 & 1273 \\
\hline Test 67 & 322 & 7.9 & 1330 & Htr 3 TC 6 & 1.46 & 0.05 & 0.11 & 1285 & 1148 \\
\hline Test 68 & 309 & 7.9 & 1320 & $\mathrm{Htr} 3$ TC 6 & 1.46 & 0.05 & 0.12 & 1279 & 1143 \\
\hline Test 69 & 323 & 8.0 & 958 & Htr 3 TC 6 & 1.46 & 0.09 & 0.16 & 1079 & 963 \\
\hline Test 70 & 312 & 8.0 & 956 & Htr 3 TC 6 & 1.46 & 0.10 & 0.17 & 1088 & 972 \\
\hline
\end{tabular}




\begin{tabular}{|c|c|c|c|c|c|c|c|c|c|}
\hline $\begin{array}{c}\text { Test } \\
\text { Number }\end{array}$ & $\begin{array}{c}\text { Inlet } \\
\text { Subcooling } \\
{[\mathrm{kJ} / \mathrm{kg}]}\end{array}$ & $\begin{array}{c}\text { Inlet } \\
\text { Pressure } \\
\text { [MPa] }\end{array}$ & $\begin{array}{c}\text { Mass } \\
\text { Flux } \\
{\left[\mathrm{kg} / \mathrm{m}^{2} \mathrm{~s}\right]}\end{array}$ & Tripped TC & $\begin{array}{l}\text { Local CHF } \\
\text { Location } \\
{[\mathrm{m}]}\end{array}$ & $\begin{array}{c}\text { Local } \\
\text { Quality [- } \\
\text { ] }\end{array}$ & $\begin{array}{c}\text { Exit } \\
\text { Quality [- } \\
\text { ] }\end{array}$ & $\begin{array}{l}q^{\prime \prime} \mathrm{CHF}, \text { local } \\
{\left[\mathrm{kW} / \mathrm{m}^{2}\right]}\end{array}$ & $\begin{array}{l}q^{\prime \prime} \text { CHF,avg } \\
{\left[\mathrm{kW} / \mathrm{m}^{2}\right]}\end{array}$ \\
\hline Test $71^{*}$ & 531 & 14.7 & 1267 & Htr 2 TC 3 & 1.33 & -0.23 & -0.13 & 1180 & 913 \\
\hline Test $72^{*}$ & 516 & 14.8 & 1258 & Htr 2 TC 3 & 1.33 & -0.21 & -0.11 & 1194 & 924 \\
\hline Test 73 & 618 & 15.1 & 1259 & Htr 4 TC 6 & 1.46 & -0.29 & -0.22 & 1020 & 912 \\
\hline Test $74^{*}$ & 504 & 14.8 & 1251 & $\mathrm{Htr} 3 \mathrm{TC} 3$ & 1.33 & -0.22 & -0.11 & 1140 & 881 \\
\hline Test $75^{*}$ & 497 & 14.9 & 1247 & $\mathrm{Htr} 3 \mathrm{TC} 3$ & 1.33 & -0.20 & -0.10 & 1160 & 897 \\
\hline Test 76 & 526 & 14.5 & 1591 & Htr 4 TC 6 & 1.46 & -0.24 & -0.18 & 1098 & 980 \\
\hline Test 77 & 530 & 14.5 & 1596 & Htr 4 TC 6 & 1.46 & -0.25 & -0.18 & 1097 & 980 \\
\hline Test 78 & 584 & 14.2 & 1579 & Htr 4 TC 6 & 1.46 & -0.28 & -0.22 & 1133 & 1012 \\
\hline Test 79 & 582 & 14.2 & 1580 & Htr 4 TC 6 & 1.46 & -0.28 & -0.22 & 1135 & 1014 \\
\hline Test 80 & 479 & 15.6 & 917 & Htr 3 TC 5 & 1.46 & -0.10 & -0.01 & 876 & 781 \\
\hline Test 81 & 471 & 15.6 & 912 & Htr 3 TC 5 & 1.46 & -0.10 & -0.01 & 856 & 763 \\
\hline Test 82 & 468 & 16.5 & 615 & $\mathrm{Htr} 4 \mathrm{TC} 8$ & 1.78 & 0.11 & 0.14 & 406 & 663 \\
\hline Test $83^{*}$ & 471 & 16.5 & 614 & Htr 3 TC 3 & 1.33 & -0.04 & 0.14 & 858 & 663 \\
\hline Test 84 & 647 & 15.6 & 1260 & Htr 4 TC 6 & 1.46 & -0.33 & -0.26 & 1022 & 913 \\
\hline Test 85 & 647 & 15.6 & 1260 & Htr 4 TC 6 & 1.46 & -0.33 & -0.26 & 1023 & 914 \\
\hline Test 86 & 591 & 15.9 & 1243 & Htr 4 TC 6 & 1.46 & -0.31 & -0.24 & 931 & 831 \\
\hline Test 87 & 590 & 15.9 & 1243 & Htr 4 TC 6 & 1.46 & -0.30 & -0.23 & 950 & 848 \\
\hline Test 88 & 632 & 16.2 & 1570 & Htr 4 TC 6 & 1.46 & -0.36 & -0.29 & 1173 & 1047 \\
\hline Test 89 & 633 & 16.1 & 1571 & Htr 4 TC 6 & 1.46 & -0.36 & -0.29 & 1173 & 1047 \\
\hline Test 90 & 595 & 16.4 & 1568 & Htr 4 TC 6 & 1.46 & -0.34 & -0.26 & 1135 & 1013 \\
\hline Test 91 & 592 & 16.4 & 1574 & Htr 4 TC 6 & 1.46 & -0.34 & -0.27 & 1117 & 997 \\
\hline Test 92 & 500 & 14.3 & 937 & Htr 3 TC 5 & 1.46 & -0.08 & 0.01 & 968 & 864 \\
\hline Test 93 & 498 & 14.3 & 935 & Htr 3 TC 5 & 1.46 & -0.08 & 0.01 & 968 & 864 \\
\hline Test 94 & 497 & 14.3 & 932 & Htr 3 TC 5 & 1.46 & -0.05 & 0.04 & 1023 & 914 \\
\hline Test 95 & 499 & 14.4 & 608 & Htr 4 TC 4 & 1.33 & 0.02 & 0.20 & 1011 & 782 \\
\hline Test 96 & 495 & 14.5 & 609 & Htr 4 TC 4 & 1.33 & 0.03 & 0.21 & 1011 & 782 \\
\hline
\end{tabular}


Additional Tripped Thermocouple Information

\begin{tabular}{|c|c|c|c|c|}
\hline $\begin{array}{c}\text { Test } \\
\text { Number }\end{array}$ & Tripped TC & $\begin{array}{c}\text { Local CHF } \\
\text { Location }[\mathrm{m}]\end{array}$ & $\begin{array}{c}\text { Local } \\
\text { Quality [-] }\end{array}$ & $q^{\prime \prime}$ CHF,local $\left[k W / m^{2}\right]$ \\
\hline Test 19 & $\mathrm{Htr} 4 \mathrm{TC} 9$ & 1.78 & 0.21 & 417 \\
\hline \multirow[t]{2}{*}{ Test 20} & Htr 4 TC 8 & 1.78 & 0.13 & 468 \\
\hline & $\mathrm{Htr} 4 \mathrm{TC} 9$ & 1.78 & 0.13 & 468 \\
\hline Test 24 & $\mathrm{Htr} 4 \mathrm{TC} 9$ & 1.78 & 0.14 & 408 \\
\hline Test 27 & $\mathrm{Htr} 4 \mathrm{TC} 9$ & 1.78 & 0.07 & 458 \\
\hline Test 32 & $\mathrm{Htr} 3 \mathrm{TC} 6$ & 1.46 & 0.25 & 744 \\
\hline \multirow[t]{2}{*}{ Test 33} & Htr 3 TC 5 & 1.46 & 0.25 & 708 \\
\hline & Htr 3 TC 6 & 1.46 & 0.25 & 708 \\
\hline Test 37 & $\mathrm{Htr} 3 \mathrm{TC} 6$ & 1.46 & 0.08 & 967 \\
\hline Test 48 & Htr 4 TC 6 & 1.46 & -0.02 & 1134 \\
\hline \multirow[t]{2}{*}{ Test 71} & $\mathrm{Htr} 3 \mathrm{TC} 3$ & 1.33 & -0.23 & 1180 \\
\hline & $\mathrm{Htr} 4 \mathrm{TC} 3$ & 1.33 & -0.23 & 1180 \\
\hline \multirow[t]{2}{*}{ Test 72} & $\mathrm{Htr} 3 \mathrm{TC} 3$ & 1.33 & -0.21 & 1194 \\
\hline & $\mathrm{Htr} 4 \mathrm{TC} 3$ & 1.33 & -0.21 & 1194 \\
\hline Test 74 & $\mathrm{Htr} 4 \mathrm{TC} 3$ & 1.33 & -0.22 & 1140 \\
\hline Test 75 & $\mathrm{Htr} 4 \mathrm{TC} 3$ & 1.33 & -0.20 & 1160 \\
\hline \multirow[t]{3}{*}{ Test 83} & $\mathrm{Htr} 3 \mathrm{TC} 4$ & 1.33 & -0.04 & 858 \\
\hline & $\mathrm{Htr} 3 \mathrm{TC} 5$ & 1.46 & 0.02 & 743 \\
\hline & Htr 3 TC 6 & 1.46 & 0.02 & 743 \\
\hline
\end{tabular}




\section{REFERENCES}

1. T. B. Drew and A. C. Mueller, "Boiling," American Institute of Chemical Engineers, pp. 449-473, 1937.

2. S. Nukiyama, "The Maximum and Minimum Values of the Heat Q Transmitted from Metal to Boiling Water under Atmospheric Pressure," International Journal of Heat and Mass Transfer, vol. 9, pp. 14191433, 1966.

3. I. A. E. Agency, "Status of Small and Medium Sized Reactor Designs," IAEA, 2012.

4. C. F. Fighetti and D. G. Reddy, "Parametric Study of CHF Data Volume 3, Part 1-2: Critical Heat Flux Data," NP-2609 Volume 3, 1982.

5. M. S. Greenwood, "PhD Dissertation: The Critical Heat Flux at Conditions Prototypical of Proposed Light Water Small Modular Reactors," University of Wisconsin, Madison, 2015.

6. IAEA, "Thermohydraulic Relationships for Advanced Water Cooled Reactors," International Atomic Energy Agency, IAEA-TECDOC-1203, 2001.

7. D. Hall and I. Mudawar, "Critical heat flux (CHF) for water flow in tubes - I. Compilation and assessment of world CHF data," International Journal of Heat and Mass Transfer, vol. 43, pp. 2573-2604, 2000.

8. S. Moon, S. Chun, S. Cho and W. Baek, "An Experimental Study on the Critical Heat Flux for Low Flow of Water in a Non-Uniformly Heated Vertical Rod Bundle Over a Wide Range of Pressure Conditions," Nuclear Engineering and Design, vol. 235, pp. 2295-2309, 2005.

9. R. J. Weatherhead, "Nucleate Boiling Characteristics and the Critical Heat Flux Occurrence in Subcooled Axial-Flow Water Systems," Argonne Illinois, 1963.

10. Y. W. Wu, G. H. Su, S. Z. Qiu and B. X. Hu, "Experimental Study on Critical Heat Flux in Bilaterally Heated Narrow Annuli," International Journal of Multiphase Flow, vol. 35, pp. 977-986, 2009.

11. S. Moon, W. Baek and S. H. Change, "Parametric Trends Analysis of the Critical Heat Flux based on Artificial Neural Networks," Nuclear Engineering and Design, vol. 163, pp. 29-49, 1996.

12. C. F. Fighetti and D. G. Reddy, "Parametric Study of CHF Data, Volume 2: A Generalized Subchannel Correlation for PWR and BWR Fuel Assemblies," NP-2609 Volume 2, 1983.

13. "TRACE V5.0 Theory Manual," United States Nuclear Regulatory Commission, Washington, D.C.

14. L. S. Tong, "Prediction of Departure From Nucleate Boiling For An Axially Non-Uniform Heat Flux Distribution," Journal of Nuclear Energy, vol. 21, pp. 241-248, 1967.

15. D. C. Groeneveld, J. Q. Shan, A. Z. Vasic, L. K. H. Leung, A. Durmayaz, J. Yang, S. C. Cheng and A. Tanase, "The 2006 CHF Look-Up Table," Nuclear Engineering and Design, vol. 237, pp. 1909-1922, 2007. 
16. A. Nafey, "Neural network based correlation for critical heat flux in steam-water flows in pipes," International Journal of Thermal Sciences, vol. 48, pp. 2264-2270, 2009.

17. H. Wei, G. Su, W. Tian, S. Qiu and W. Ni, "Study on the characteristic points of boiling curve by using wavelet analysis and genetic neural network," Nuclear Engineering and Design, vol. 239, pp. 2317-2325, 2009.

18. H. Wei, G. Su, S. Qiu, W. Ni and X. Yang, "Applications of genetic neural network for prediction of critical heat flux," International Journal of Thermal Sciences, vol. 49, pp. 143-152, 2010.

19. H. Wei, G. Su, W. Tian, S. Qiu and X. Y. W.F. Ni, "Study on dryout point by wavelet and GNN," Applied Thermal Engineering, vol. 30, pp. 664-672, 2010. 